\title{
A Study on Two New Chinese Mandarin Phrases “Jiang Zhen” (讲真) and "Lao Siji” (老司机) from the Three Dimensions of Language
}

\author{
Aihua Wen ${ }^{1}$ \\ ${ }^{1}$ Institute for International Education, Guangdong University of Foreign Studies, Guangzhou, China \\ Correspondence: Aihua Wen, Institute for International Education, Guangdong University of Foreign Studies, \\ No.2 North Baiyun Ave, Guangzhou, Guangdong, China. Tel: 86-155-2120-1856.
}

Received: January 24, 2017

Accepted: February 22, 2017

Online Published: March 8, 2017

doi:10.20849/aes.v2i1.119

URL: https://doi.org/10.20849/aes.v2i1.119

\begin{abstract}
Internet users have given two existing phrases in Chinese, "Jiang Zhen" and "Lao Siji" new second definitions. "Jiang Zhen" which exists in some southern Chinese dialects is gradually becoming a new Mandarin phrase. The phrase's meaning is being transformed and this new meaning is being used by Chinese netizens. This new and transformed meaning has spread quickly throughout the internet. On the other hand, "Lao Siji" now has several new meanings and has become more popular in online and real life conversations. From the three dimensions of language namely semantics, syntax and pragmatics, the two new phrases have their intrinsic connotations. Currently, different sections of the public hold different attitudes to these two new phrases, so their vitality is still waiting for the test of time.
\end{abstract}

Keywords: "Jiang Zhen", "Lao Siji", semantics, syntax, pragmatics, vitality

\section{The Study on "Jiang Zhen" from the Three Dimensions of Language}

Since 2015, "Jiang Zhen" has gradually become popular across the internet and has now become a new network phrase. As is known to all, the reason these new phrases or expressions circulate is because they are novel and allow users to express their individual personalities. At first glance, "Jiang Zhen" is not new because it already exists in some Chinese dialects. Similar expressions can also be found in some southern Chinese dialects such as Cantonese, Min Dialect, Wu Dialect, Kejia Dialect, Gan Dialect and Xiang Dialect. In all of these dialects, “jiang" (讲) or "hua" (话) is used to replace "shuo" which is used in Mandarin and the pronunciation of "jiang" (讲) is similar to “gang” (港) and the pronunciation of “hua" (话) is similar to “wa” (哇). Furthermore, some phrases or expressions are also used in Mandarin such as "Shuo Zhen De" (说真的) which has a similar meaning to "Jiang Zhen". However, further analysis shows that traditional Mandarin only has the expression "Shuo Zhen De" (说真的) but not the two syllabled "Shuo Zhen" (说真) or "Jiang Zhen". Analogously, "Jiang Zhen" or "Hua Zhen" (话真) should plus the structural auxiliary word "De" (的) or other additional components in the southern dialects. For example, the Cantonese dialect has "Jiang Zhen Ge" (讲真嘅) or "Jiang Zhen Ge Ju" (讲 真個句) (Note 1), the Min Dialect has “Jiang Zhen Ei" (讲真欱), the Wu Dialect has "Jiang Zhen Nong" (讲真 哝) or “Jiang Zhen Ei”(讲真诶), the Kejia Dialect has "Hua Zhen Ga" (话真噶), the Gan Dialect has “Jiang Zhen Ge" (讲真个) or "Hua Zhen Ge" (话真个), and the Xiang Dialect has "Jiang Zhen Di" (讲真滴). In these dialects, the expression seems incomplete if "Jiang Zhen" is used without any other components. But the internet buzz phrase "Jiang Zhen" that comes from and is used in Mandarin does not have the auxiliary word "De" or other components. From this, the simple phrase "Jiang Zhen" in Mandarin does possess the characteristic of novelty, and the phrase has achieved this mainly through the following two methods:

1. Removing and Grafting. Compared with "Shuo Zhen De" in Mandarin or "Jiang/Hua Zhen+De/other components" in dialects, "Jiang Zhen" shakes off "De" and other components, making it a new phrase in Mandarin (Note 2). Although in Mandarin and dialects, the structure "Jiang/Hua Zhen+De/other components" has long been in existence, the novelty of "Jiang Zhen" is still quite obvious. Therefore, from the removal of "De" and other components, "Jiang Zhen" is essentially an abbreviation.

2. By leaving out the "De" and other components in the structure used in the dialects and converting "Jiang Zhen" directly into Mandarin will enhance the effect of its strangeness and individualization.

Based on our study, the phrase "Jiang Zhen" originates from online live streaming, including live interaction 
posts and live games such as Dounai live (Note 3), LOL live and DOTA live where the anchors frequently use "Jiang Zhen". The audiences who are largely young people then circulate this phrase among themselves. The following examples are provided to study "Jiang Zhen" from the three dimensions of language, namely semantics, syntax and pragmatics.

(1) Jiang Zhen, Guochan (国产) Ju (剧) Yao (要) Neng (能) Dou (都) Zheyang (这样) Pai (拍), Chu (出) Yibu (一部) Wo (我) Kan (看) Yibu (一部) (Note 4)! (To be honest, if home-made movies are all like this, I will watch every one of them as soon as they come out.)

(2) Jiang Zhen, Zhongguo (中国) Yinxing (隐形) Fuhao (富豪) Dou (都) Kai (开) Shenme (什么) Che (车) (Note 5)? (To be serious, what cars do the Chinese invisible rich drive?)

(3) Jiang Zhen, Guge (谷歌) Wuren (无人) Jiashi (驾驶) Qiche (汽车) Qiantu (前途) Zai (在) Nar (哪儿) (Note 6)? (Frankly, What is the prospect of a Google autonomous vehicle?)

(4) Jiang Zhen, HTC Daigong (代工) De (的) Pixel Shouji (手机) Chabuduo (差不多) Jiu (就) Zheyang (这样) Le (了) (Note 7). (To tell the truth, The Google pixel mobile phone manufactured by HTC is probably like this.)

(5) Jiang Zhen Tianya (天涯) Tu (途) Shang (上) Shei (谁) Shi (是) Ke (客), Sanxi (散席) Shi (时) Zenme (怎么) Fen (分) (Note 8). (Frankly, in the journey of the world, how can you tell who are the guests when the banquet is over.)

From semantic perspective, "Jiang Zhen" has the following meanings: frankly, to tell the truth, to be honest, to be serious, to be realistic and so on. It is mainly used to express the real opinions or attitudes of the two parties engaged in communication. The five examples mentioned above in sense try to emphasize this: if home-made movies can really be like this; what car do the Chinese invisible rich really drive; what is the real prospect of a Google autonomous vehicle; a Google pixel mobile phone manufactured by HTC is probably like this; In the journey of the world, who is really the guest. "Jiang Zhen" itself doesn't have positive or negative meaning in a sentence, but the whole meaning of the sentence can be positive, negative or neutral.

From syntactic perspective, "Jiang Zhen" is generally put at the beginning of a sentence and functions as a parenthesis. Furthermore, there is usually a comma between it and the other parts of the sentence, see example (1) - (4). Although there is no comma following it in example (5), it still belongs to a parenthesis. Therefore, the use of "Jiang Zhen" in the five examples can be seen as a parenthesis of the sentence. Apart from example (5) which belongs to artistic creation-lyric, "Jiang Zhen" in the other four examples can also serve as post parenthesis, For example:

(6) Guochan Ju Yao Neng Dou Zheyang Pai, Chu Yibu Wo Kan Yibu! Jiang Zhen (Note 9).

(7) Zhongguo Yinxing Fuhao Dou Kai Shenme Che? Jiang Zhen.

(8) Guge Wuren Jiashi Qiche Qiantu Zai Nar? Jiang Zhen.

(9) HTC Daigong De Pixel Shouji Chabuduo Jiu Zheyang Le, Jiang Zhen.

Whether it is used as front parenthesis or post parenthesis, the syntactic function of "Jiang Zhen" is similar to "Shuo Zhen De" in Mandarin, but "Shuo Zhen De" can also function as a predicative apart from parenthesis, for example:

(10) Wo (我) Gen (跟) Ni (你) Shuo (说) Zhen De (真的) Ne (呢), Ni (你) Bie (别) Bu (不) Danghuishi (当回 事). (I am talking to you seriously, don't be flippant.)

(11) Ni (你) Shuo (说) Zhen De (真的) Ma (吗)? (Are you serious?)

However, example 12 and 13 are expressions that do not currently exist in Mandarin because they do not make sense.

(12)* (Note 10) Wo (我) Gen (跟) Ni (你) Jiang Zhen Ne (呢), Ni (你) Bie (别) Bu (不) Danghuishi (当回事).

(13) * Ni (你) Jiang Zhen Ma (吗)?

From the perspective of pragmatics, "Jiang Zhen" is used to convey the real thoughts of the speaker and sounds formal and serious for the purpose of arousing the attention of the listener. The word has different functions in pragmatics when used in written and oral from. Generally, the popularization of a new Chinese word starts from the internet, especially in the written form as Characters. Characters are more uniform than spoken Chinese and they spread faster, wider and further than spoken phrases through the internet. Currently, "Jiang Zhen" is used more frequently when writing rather than speaking. The written "Jiang Zhen" combined with other traditional Mandarin words will cause more intense visual freshness from those who support the use of this phrase and 
disgust from those who are against it.

During the process of popularization and broadcasting, a new word will have to face the acceptance and attitude of the population. At the present, people hold mixed attitudes towards "Jiang Zhen" as listed below:

1. Agree. Those who agree think "Jiang Zhen" is new, concise and has linguistic individuality and should be promoted, and they questioned why the word "Huyou" (忽悠) (Note 11) in the Northeastern Dialect can be popular but "Jiang Zhen" can't. However, actually, from a deeper level, it has something to do with the different origins of them. "Huyou" is rooted in northern dialects which are the source of Mandarin and covers a large area. Besides, with the promotion of song and dance duets, sketches and other art forms, "Huyou" is gradually expanding out of the northern provinces. In addition, TV shows, especially TV series and other programs presented by CCTV and some northern TV stations have also helped to promote and broadcast this word, making it familiar south of the Yangtze River and known to the southern dialect areas. In a different way from "Huyou", the popularization of Cantonese words or phrases like "Dagong" (打工) (Note 12) and "Maidan" (买单) (Note 13) are the result of their frequent use in economics and daily life after reform and opening up. As Canton's economy is making great progress and they have gradually become legally recognised Mandarin expressions used across the whole China. Of course, Cantonese is also one of the origins of "Jiang Zhen", and "Jiang Zhen" has already become a new network phrase of Mandarin, but it is not known whether this phrase will make sense and become a legally recognized phrase in Mandarin at present.

2. Disagree. It is reasonable that "Jiang Zhen" can be used in southern dialects, but it would seem unnatural and uncomfortable when combined with other Mandarin elements especially when it is used by non-southern dialect users, and these non-southern dialect speakers get called "mere copycats"by those who disagree.

3. Neutral. Some believe that the existence of "Jiang Zhen" has its own reasons. The great German philosopher G. W. F. Hegel once said what is reasonable is real, that which is real is reasonable. Therefore, neutrals say that any word or phrase has its reason for being, if you like it, you can use it, otherwise there is no need to criticize it. This is because as time goes by, the novelty of it will eventually disappear and eventually nobody will carry on using it.

Thus it can be seen that the attitudes of people towards this phrase more or less depends on which dialect zone they live in. If the recipient is a southerner, he is more likely to accept this expression than a northerner because he or she has a similar expression in his or her dialect. However, that higher acceptance is only limited to southern dialect speakers who use "Jiang Zhen" in Mandarin, whereas it is less acceptable for southerners when northerners are using it.

\section{The Study on "Lao Siji" from the Three Dimensions of Language}

“Lao Siji” (老司机) which literally means an experienced driver, but from a translation derived from a folk song in Yunnan Province it means a veteran. It has then spread on the internet and in reality. This phrase's popularity has gradually risen in online comments on social networks and IM. Since 2015 it has become more and more common in young and educated people's discourse. From the perspective of origin, "Lao Siji" is not a new phrase like "Jiang Zhen", but users have created new meanings for it and it is now regarded as a completely new phrase. There are two key semantic points of it, one is indicated by "Lao" (老) which means experienced, skilled or sophisticated, and another one is indicated by "Siji" (司机) which means drive vehicles like cars, buses, trains or even ships (Note 14). It is then extended in some new meanings to mean lead, control, manage or handle something or somebody and so on. In a word, based on the literal meaning namely an experienced driver, "Lao Siji" has four extended meanings arranged according to the relation with its etymon from close to loose as the following:

1. A womanizer. (Note 15) It originates from a Yunnan folk named “Lao Siji Daidai (带带) Wo (我)" (Pick me up, the experienced driver) which is sung by Gengjing and Lin Meng. On the MV, two young and beautiful girls stand at road to stop a truck and ask the driver to pick them up and take them downtown, but when they ask for this favour, it is a kind of sexual provocation. Essentially, the lyrics are rather pornographic and undisguised such as lip, tit, waist, ass, belly and leg expose that provocation more obviously.

2. A man who is good at hooking up with women, like Don Juan. Chinese call a man who is good at attracting and hooking up with women "Lao Siji", because he is good at manipulating women.

3. A person who has many rare, secret, and precious online resources that are hard for the public to get such as some old pictures, photos, E-books, movies, or even something difficult to display in public like pornographic images and videos. The resource owner enjoys sharing and posting the resources in the form of links. This is an extended and integrated meaning from the $1^{\text {st }}$ and $2^{\text {nd }}$ meaning above because of their derogatory meanings like 
porn and sex. Further, some expressions come up based on this meaning, for example:

(14) Lukuang (路况) Lianghao (良好), Suishi (随时) Keyi (可以) Fache (发车). Shangche (上车) Qing (请) Shuaka (刷卡), Kaiche (开车) Le (了)!(It literally means “The road is in a good condition, the bus can depart at any time. Please scan your card when getting on, let's go" but it actually means "I am ready to share the resources that you need, are you ready? GO".)

(15) Kuai (快) Shangche (上车), Laibuji (来不及) Jieshi (解释) Le (了)! (It literally means “There is no time to explain, get in" but it actually means "There is no time to explain what the online resources I shared are, just download them by following my links", and then it tends to mean "No time to explain, just follow my guidance".)

(16) Lao Siji Daidai (带带) Wo (我). (It literally means “Pick me up, the experienced driver" but it actually means "Share me some online resources, the resource owner".)

(17) Lao Siji You (又) Fache (发车) Le (了). (It literally means “The experienced driver departed his car again” but it actually means "The owner shared more resources online".)

4. The person who is experienced and sophisticated in a certain industry. He or She is so familiar with the skill, rule, work, process, schedule, right, obligation, relation and so on. Normally, this person is often knowledgeable, senior and also has a broad horizon.

In the 4 cases above, "Lao Siji" is a respectful address given by his or her followers but with a humorous semantic to some degree. Furthermore, it may change to become ironic when he or she fails in sharing online resources or handling something. For example:

(18) Lao Siji Fanche (翻车) Le (了)! (It literally means "The car driven by the experienced driver has rolled over" but it actually means "The owner failed in sharing online resources" or "The experienced person failed at something".)

(19) Zhe (这) Jianzhi (简直) Shi (是) Chehuo (车祸) Xianchang (现场)! (It literally means “This is the scene of the car accident" but it actually means "How terrible the failure is"!)

Lao Siji's failure makes the people who want to get resources or experience from him or her disappointed, so the phrase "Lao Siji" goes through a subtle change in pragmatics which is from a positive to a negative one to indicate ridicule.

From the perspective of syntax, since "Lao Siji" is a noun phrase, it can normally function as a subject or object in Chinese, for example:

(20) Lao Siji Dou (都) Zhidao (知道) Zhege(这个). (Veterans all konw this.)

(21) Ni (你) Zhen (真) Shi (是) Yige (一个) Lao Siji ! (You really are a veteran!)

For the requirement of studying language longitudinally, this paper is also intended to predict the vitality of "Jiang Zhen" and "Lao Siji". "Jiang Zhen" is one of the few phrases that is almost only active in written from. Other recent buzz phrases or expressions like "Zhongyao (重要) De (的) Shiqing (事情) Shuo (说) San (三) Bian (遍)”, “Youyi (友谊) De (的) Xiaochuan (小船) Shuo (说) Fan (翻) Jiu (就) Fan (翻)”, “Ge You (葛优) Tan (瘫)" and “Yiyanbuhe (一言不合) Jiu (就)" have all become popular orally after they become vogue in the written form on the internet. Despite that, it is different in the case of "Jiang Zhen". Without the support of oral transmission, the promotion of "Jiang Zhen" will be undoubtedly be hindered. On the other hand, during online chat and communication typed in Chinese Characters, "Jiang Zhen" is frequently used but is only limited to the folk. "Lao Siji" is frequently used in virtual and subsistent communication, but neither of them have been collected by academic corpus such as Peking University corpus CCL (Note 16), nor by any news corpus, but only seen in some fragmental news texts. As a result, the examples given in this paper all come from fragmental news texts or self-compiled texts. However, due to the delay of corpus admitting new words, "Jiang Zhen" and "Lao Siji" may also be collected in the future, but it is a long shot whether they will get the recognition of "PK" (Note 17) to be added to the dictionary. Finally, we would like to say that only time will tell whether these two new phrases will become active volcanoes, extinct volcanoes or dormant volcanoes in language terms.

\section{Conclusion}

This paper mainly studies the two new Chinese Mandarin phrases "Jiang Zhen" and "Lao Siji" from the three dimensions of Language, and finds that they have many meanings in semantics, different functions in syntax and pragmatics of their use. They are novel phrases among the young and educated people at present, but it is not easy to predict their vitality leading into the future. 


\section{References}

Kong, D. (2017). Lao Siji Has Been Added New Meanings. Language Planning, 5.

Li, L. (2007). A Study on Network Language, Doctoral Dissertation of Shaanxi Normal University.

Ni, Y. (2016). Jiang Zhen, Is It Possible to Be Less Routine. Science and Technology Daily, 7.

Ning, D. (2016). Lao Siji. The life of the Chinese People's Liberation Army, 9.

Shi, C. (2010). The Language and Linguistic Value of Network language. Applied Linguistics, 3.

\section{Notes}

Note 1. It is rather popular to say "Jiang Zhen" only as well.

Note 2. "Jiang Zhen" is a new phrase only in Chinese Mandarin, so what analyzed in this paper is the phrase "Jiang Zhen" in Mandarin instead of dialects.

Note 3. It is a famous live video streaming supports bullet screen.

Note 4. Source: http://news.gmw.cn/2016-10/03/content_22283641.htm

Note 5. Source: http://auto.sohu.com/20160923/n469012368.shtml

Note 6. Source: http://www.leiphone.com/news/201609/IrXWTbBQ9zWHquKF.html

Note 7. Source: http://mobile.163.com/16/1004/00/C2GB277T00118026.html

Note 8. Source: from the lyrics of a song named “Luohua Liushui (落花流水)" which is written by Wyman Wong and sung by Eason Chan.

Note 9. Example (6) - (9) have the same meanings as example (1) - (4) respectively.

Note $10 . *$ means the sentence is wrong and does not make sense in Chinese syntax.

Note 11. It means cheat.

Note 12. It means work for others

Note 13. It means pay the bill.

Note 14. So "Lao Chuanzhang (船长)" which means an experienced captain replaces "Lao Siji” sometimes.

Note 15. A driver implies a womanizer because most drivers are male.

Note 16. Center for Chinese Linguistics of Peking University.

Note 17. It means play and kill (or beat down) the opponents.

\section{Copyrights}

Copyright for this article is retained by the author(s), with first publication rights granted to the journal.

This is an open-access article distributed under the terms and conditions of the Creative Commons Attribution license (http://creativecommons.org/licenses/by/4.0/). 